\title{
Athletes' Stress Determinants when Countering Fear of Failures at Their Training Center Program
}

\author{
Heny Setyawati ${ }^{1}$, Didik Rinan Sumekto ${ }^{2}$, Nur Haziyanti ${ }^{3}$, Fatona Suraya ${ }^{4}$, Sungkowo ${ }^{5}$, \\ Thania Kusumaningtyas ${ }^{6}$, Laksmana Pandu Pratama ${ }^{7}$ \\ \{henysetyawati@mail.unnes.ac.id ${ }^{1}$, didikrinan@unwidha.ac.id ${ }^{2}$, nur.haziyanti@fsskj.upsi.edu.my ${ }^{3}$ \} \\ Universitas Negeri Semarang, Semarang, Indonesia ${ }^{1,}$ \\ Widya Dharma University, Klaten, Indonesia ${ }^{2}$, \\ Universiti Pendidikan Sultan Idris, Perak, Malaysia ${ }^{3}$
}

\begin{abstract}
Self-confidence is automatically influential towards athletes' performance. This research aims to reveal the professional athletes' determinants constituting with their individual experience at the Regional Training Center Program. 290 in-training program athletes at the Training Center, the Indonesian National Sports Committee of Central Java Province, Indonesia were involved to be the respondents. Data were collected from self-rated questionnaire with a 5-Likert scale. Data analysis used the SPSS program for revealing athletes' stress determinants. The results showed the mean of excessive exercise training $(\mathrm{M}=4.51, \mathrm{SD}=.885)$, hedonic lifestyle $(\mathrm{M}=3.17, \mathrm{SD}=$ $1.00)$, aversive stimulation $(\mathrm{M}=3.51, \mathrm{SD}=.985)$, and overload competition $(\mathrm{M}=4.25$, $\mathrm{SD}=.719)$ were significant. Meanwhile, the factorial analysis claimed that two-fixed components gained $44.84 \%$ of the variances (first component $=31.69 \%$; second component $=13.15 \%$ ). These determinants coherently accomplish a comprehensive examination to strengthen athletes' self-confidence in the training program.
\end{abstract}

Keywords: athletes' self-confidence, countering failures, stress determinants

\section{Introduction}

Athletes' stress triggers careful changes, such as focus narrowing, general confusion, and increased self-consciousness, which interfere with success of athletes. Herein, the stress methods of coaching athletes have demonstrated a decrease in the amount of injury levels over a season of their training center program or level of participation. [1] confirm that stress appears often as athletes practice for professional competition. The appearance includes physiological and physical symptoms, such as leading stomach weight, throat lumping, sleeping disorders, and heart palpitation, as well as can come from non-training areas and social pressure [2]. [3] points out that stress as an extreme pressure or stress imposes on a body expressed per area unit is seen as the way human beings react to situations that frighten, intimidate, or excite them. When these problems continue, there is a tendency in the human cognitive process to break down tiredness, or even damage to the body's immunity system that can result in the mental failure. Another understanding, stress is a key principle for understanding both life and evolution, fulfilling the adaptive responses depending on the capacities of the strong athletes [4]. 
Current concepts of stress also agree that stress is a personal experience induced by pressure or demands on an individual and influences the capacity of the individual to cope with that task, or rather, their understanding of it. Usually, stress issues have complex and various causes and cannot be related exclusively to incidents in the training centre program [4]. In the context of determining the most appropriate stress management intervention, the role of assessment within the stress process is central. Specifically, the stress management mitigation strategy indicates performers are responding to demands with negative effects on performance. Of this conditional effort, the athletes can afford the following three steps to reduce their stress, namely: firstly, athletes learn the fundamentals of skills in a stress-free atmosphere by working closely with the practitioner; secondly, by raising their freedom from the practitioner, athletes are more self-directed and begin to apply their skills in nonhazardous situations; and thirdly, athletes are advised to use them and also to test the efficacy of their skills; in a stressful, non-sport environment [5]. Further, [6] re-explained three main points in overcoming athletes' stress, namely: managing the stress of preparation, managing the stress of competition and managing daily stress.

In sports psychology, stress is seen as a source of excitement that is directly linked to the particular task requirement of the demand that a situation imposes on person competing in competitive sports in order to achieve excellent results, while others believe that stress has devastating effects on psychological health, stress can be good or bad [3]. As the earlier information, sports are classified into two general types, namely: dynamic (e.g.: producing a volume load on the left ventricle) and static (e.g.: producing a pressure load on the left ventricle) sports, which endorsed to the intensity level (low, medium, high) and the presence or absence of a collision for contextual factor [7]. These two types of sports potentially cause with the athletes readiness or failures when they are not ready to manage it. Consequently, the competitive training programs of some athletes provide some sort of stress management that focuses on achieving an optimal mental state of pre-performance [5]. Herein, athletes' life experience upon their stress can be confirmed that the athlete felt that when anything to be positive happened, she was just optimistic. Then she replied, "I'm bothered by how I feel, as if I'm not sure how I'm playing so I don't think I 'm helping the team and I'm starting to get down on myself." Meanwhile, another athlete said that she did not have a lot of selfconfidence either. When she was asked, "How confident are you in team's ability to succeed?" She replied, "Truly confident. I never think I'm doing good as an individual, but we're successful as a team." [8].

Some previous researches on athletes' stress determinants participating in sports performance, management, and stress relieving effects helped athletes alleviate tension during their sport performance and training outputs. On the other hand, over-stressed including overloading, burning out, dropping out and developing maladaptive fatigue syndrome affected the mental health of athletes, such as perceptions of psychological, emotional, and behavioral issues in their training schedule [6]. Next, [1] emphasized that the comparison of physical and psychological stress symptoms revealed significant differences between the recorded scores. Accordingly, we noted a slight effect of symptom of muscle tension and main motivational effect. Whereas the findings of the physiological, mental, emotional, and existential ratings of psychological stress symptoms were strongly consistent. On the other hand, stress had been shown to adversely affect both psychological and physical health. Individuals with chronic stress were at higher risk for severe health problems such as rheumatoid arthritis, cardiovascular disease and other cancers as well as mental health issues such as anxiety, depression, disordered eating and alcohol use [9]. [10] reinforced that a number of stress 
reduction approaches were related to increased stress awareness and improved results for athletes. The results indicated that a variety of diverse design features, for example: treatment implemented and stress function outcome measured influence the effectiveness of stress management. Such design features were essential when developing treatments for athletes of varying sports, ages, and overall competitive standards. Last but not least, importantly, the awareness of athletes in the situation triggered the affective reaction, which demonstrated the importance of mental toughness in recognizing the perceived stress level of athletes as well as the affective stress response. Emotions also tended to play a significant role in the practice of developing junior athletes towards professional sports [11].

This research relied on two research questions regarding athletes' stress determinants as revealed at their sports training center program, as follows: (1) Do athletes' stress determinants influence their self-confidence when joining in the sports training center program? (2) Can athletes' sports performance manage some deficiencies as driven by the stress determinants? This research addresses a self-rated questionnaire with a 5-Likert scale and attempts to highlight the purposeful aims. As stated in the literature review, this research investigates athletes' stress determinants as revealed at their sports training center program, handled by the Indonesian National Sports Committeeof Central Java Province, Indonesia.

\section{Methods}

This research brought about 290 out of 451 athletes from the various sport fields at the Training Center Program using simple random sampling technique. These 290 athletes officially joined in the Indonesian National Sports Committee Registry of Central Java Province, Indonesia and were randomly selected to be the respondents. The obtainable data were carried out from the self-rated questionnaire figuring out of athletes' stress determinants as revealed at the training center program. The scaling system was purposely indicative with a 5 -point Likert scale rubric to record athletes' individualized ratings of mood $(5=$ highly stressed, $4=$ stressed, $3=$ moderately stressed, $2=$ slightly stressed, $5=$ unstressed). This rubric was modified through a rigid content-validation process to adjust the indicators in each determinant. The stress determinants involved four influential values, namely: the excessive exercise training, hedonic lifestyle, aversive stimulation, and overload competition.

These determinants were initially aligned by the Cronbach's alpha reliability test [12] that accommodated other thirty-five athletes, who also joined in the training center program at the Indonesian National Sports Committee Registry of Central Java Province, Indonesia. The Cronbach's alpha internal consistency of athletes' stress determinants found their following alpha $(\alpha)$ value: .797 for athletes' excessive exercise training, .748 for athletes' hedonic lifestyle, .695 for athletes' aversive stimulation, .702 for athletes' overload competition. Data analysis used descriptive statistics, Pearson correlations, and factor analysis tests [13], which established the values of four perceived athletes' stress determinants deriving the principal components analysis with the Eigenvalue [14] to indicate athletes' stress levels that triggered their self-confidence during joining in the training center program. All statistical analyses completely applied for the IBM SPSS Statistics software, version 20 software packages to data processing. 


\section{Results and discussions}

First of all, this descriptive analysis that was in accordance with athletes' stress determinants corresponded with the descriptive and frequencies statistics results (TABLE 1 and Fig. 1). The determinant of excessive exercise training descriptively gave evidence of 6 $(2.1 \%)$ athletes were unstressed, $9(3.1 \%)$ athletes were slightly stressed, $14(4.8 \%)$ athletes were moderately stressed, $63(21.4 \%)$ athletes were stressed, and $199(68.6 \%)$ athletes were highly stressed if they experienced with their excessive exercise training. The result also confirmed that the highest score of athletes' excessive exercise training raised $5.00(\mathrm{M}=4.51$; $\mathrm{SD}=.885 ; \mathrm{n}=290$ ). The empirical evidence of athletes' stress established highly stressed level with the frequency of 199 (68.6\%). To be most effective, mental and physical symptoms require specific and individual psychological competency programs. This feature applies to the frameworks for both reduction and restructuring. For example, a performer who has high physical anxieties will typically be offered a somatic (i.e., physical) relaxation procedure, such as gradual muscle relaxation, through the reduction method, Trying to balance diagnosis with physical reaction [5]. Anyway, the sport psychological profile can predict competitive anxiety, moods, and self-efficacy scores, and coping control in these predictive models is one of the most relevant dimensions of this. Similarly, self-confidence is the predictor that best predicts the psychological profile of athletes, in particular through positive coping management, attitude regulation and careful monitoring [15]. The most notable symptom of stress is based on symptoms of muscular tension. Therefore it appears that stress is induced by observable apprehensive conduct and was evidenced by discomfort or cramps in some of the muscles of the body before the match. This condition can also be felt during sports as muscle spasms, twitching, 'clamping up' and constant pain during sports event [1].

Table 1. Athletes' Excessive Exercise Training

\begin{tabular}{|c|c|c|c|c|}
\hline Likert's Scale & $\begin{array}{l}\text { Fre- } \\
\text { quency }\end{array}$ & Percent & Valid Percent & $\begin{array}{r}\text { Cumulative } \\
\text { Percent }\end{array}$ \\
\hline 1.00 (Unstressed) & 6 & 2.1 & 2.1 & 2. \\
\hline 2.00 (Slightly stressed) & 9 & 3.1 & 3.1 & 5.2 \\
\hline 3.00 (Moderatelystressed) & 14 & 4.8 & 4.8 & 10.0 \\
\hline 4.00 (Stressed) & 62 & 21.4 & 21.4 & 31.4 \\
\hline 5.00 (Highly stressed) & 199 & 68.6 & 68.6 & 100. \\
\hline Total & 290 & 100.0 & 100.0 & \\
\hline
\end{tabular}




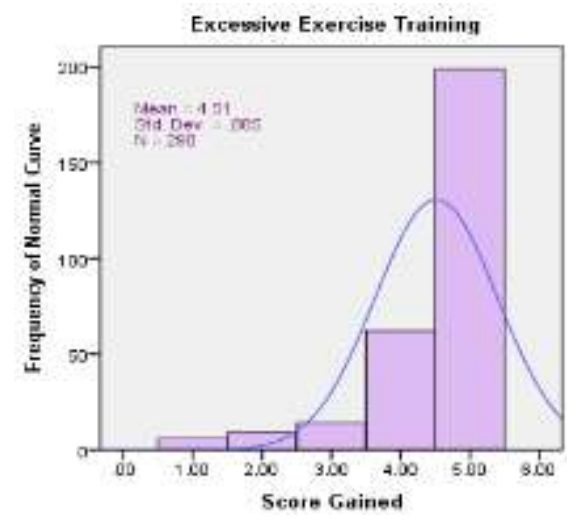

Fig. 1. Histogram on athletes' excessive exercise training

Second, the analyses of hedonic lifestyle (TABLE 2 and Fig. 2) were summarized in the following description: $12(4.1 \%)$ athletes were unstressed, $57(19.7 \%)$ athletes were slightly stressed, $119(41.0 \%)$ athletes were moderately stressed, 71 (24.5\%) athletes were stressed, and $31(10.7 \%)$ athletes were highly stressed when they spent times to have the hedonic lifestyle. The result also confirmed that the highest score of athletes' hedonic lifestyle earned $3.00(\mathrm{M}=3.18 ; \mathrm{SD}=1.00 ; \mathrm{n}=290)$. The empirical evidence of athletes' stress found moderately stressed level with the frequency of 119 (41.0\%).The impact of eating disorders, depression and suicide, anxiety and stress, over-training, sleep disorders and attention deficit or hyperactivity disorder triggered to athletes' worse hedonic lifestyle [16]. This case might be badly impacted either since athletes were failed to show lower prevalence of hypertension with adherence to routine exercise training and a balanced lifestyle. Therefore, changes in lifestyle were enough to maintain maximum regulation of blood pressure levels [17].

Table 2. Athletes' hedonic lifestyle

\begin{tabular}{lllll}
\hline \multicolumn{1}{c}{ Likert's Scale } & \multicolumn{1}{c}{ Frequency } & Percent & $\begin{array}{l}\text { Valid } \\
\text { cent }\end{array}$ & $\begin{array}{l}\text { Per- } \\
\text { Percent }\end{array}$ \\
\hline 1.00 (Unstressed) & 12 & 4.1 & 4.1 & 4.1 \\
2.00 (Slightly stressed) & 57 & 19.7 & 19.7 & 23.8 \\
3.00 (Moderately stressed) & 119 & 41.0 & 41.0 & 64.8 \\
4.00 (Stressed) & 71 & 24.5 & 24.5 & 89.3 \\
5.00 (Highly stressed) & 31 & 10.7 & 10.7 & 100.0 \\
\hline Total & 290 & 100.0 & 100.0 & \\
\hline
\end{tabular}




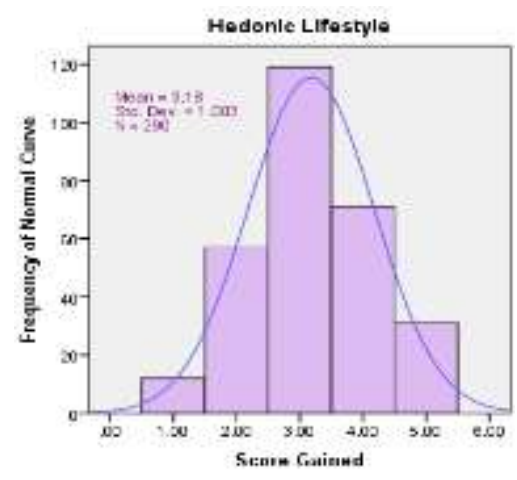

Fig. 2. Histogram on athletes' hedonic lifestyle

Third, the analyses of aversive stimulation (TABLE 3 and Fig. 3) were due to the following description: $4(1.4 \%)$ athletes were unstressed, $41(14.1 \%)$ athletes were slightly stressed, $98(33.8 \%)$ athletes were moderately stressed, $96(33.1 \%)$ athletes were stressed, and $51(17.6 \%)$ athletes were highly stressed when they were ignorant and led to the aversive stimulation. The result also confirmed that the highest score of athletes' aversive stimulation was $3.00(\mathrm{M}=3.51 ; \mathrm{SD}=.985 ; \mathrm{n}=290)$. The empirical evidence of athletes' stress found moderately stressed level with the frequency of 98 (33.8\%). The description of aversive stimulation relied on the athletes who were positive and had strong approaches to dealing with chronic stress. Alternatively, if the stressed athletes were biologically vulnerable due to age, genetic, or constitutional factors, they were deeply intense and too persistent to suffer from the disease. These athletes faced the real condition if they had little psycho-social support and weak coping skills [4]. Therefore, athletes were required to test the long-term efficacy of motor-mental rituals and to evaluate the efficacy of additional innovative personality to boost their performance [18]. Besides engaging the awareness of the individual reactions to the rehabilitation incentive and the effects of other factors were critical for predicting the rehabilitation and carrying out supporting interventions for athletes [19]. Specifically, athletes' moods assistance identified whether athletes were adapting to training loads and competition. Mood indicators could detect processes such as over-training or problems to adapt psychologically to athletes stress. Likewise, the data suggested that a good development of aspects could contribute to a lower development of negative feelings and an increase in adaptive moods. Thus, coaches could use these indicators to assess how the athletes approached the competition and helped them [15]. If an athlete lacked motivation or the most modest amount of arousal to stay focused and get going, his or her performance on various tasks was likely to suffer [1]. This could array through their facial expression, voice sonority and loudness, and gestural movements [20] as the indication of showing the stress levels.

Table 3. Athletes' aversive stimulation

\begin{tabular}{lllll}
\hline \multicolumn{1}{c}{ Likert's Scale } & Frequency & Percent & $\begin{array}{c}\text { Valid } \\
\text { Percent }\end{array}$ & $\begin{array}{c}\text { Cumulative } \\
\text { Percent }\end{array}$ \\
\hline 1.00 (Unstressed) & 4 & 1.4 & 1.4 & 1.4 \\
2.00 (Slightly stressed) & 41 & 14.1 & 14.1 & 15.5 \\
3.00 (Moderately stressed) & 98 & 33.8 & 33.8 & 49.3 \\
4.00 (Stressed) & 96 & 33.1 & 33.1 & 82.4 \\
\hline
\end{tabular}




\begin{tabular}{lllll}
\hline 5.00 (Highly stressed) & 51 & 17.6 & 17.6 & 100.0 \\
\hline Total & 290 & 100.0 & 100.0 & \\
\hline
\end{tabular}

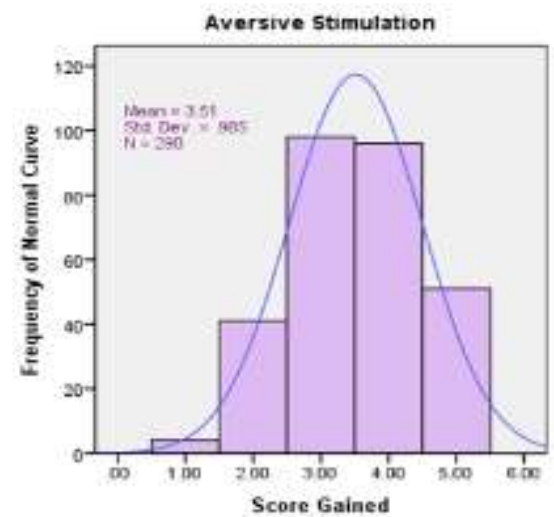

Fig. 3. Histogram on athletes' aversive stimulation

Fourth, the analyses of overload competition (TABLE and Fig. 4) related to the following findings: $1(.3 \%)$ athletes were unstressed, $4(1.4 \%)$ athletes were slightly stressed, 29 $(10.0 \%)$ athletes were moderately stressed, 141 (48.6\%) athletes were stressed, and 115 $(39.7 \%)$ athletes were highly stressed when they spent a lot of times with their overload competition schedules. The result also confirmed that the highest score of athletes' overload competition gained $4.00(\mathrm{M}=4.26 ; \mathrm{SD}=.719 ; \mathrm{n}=290)$. The empirical evidence of athletes' stress engaged in stressed level with the frequency of 141 (48.6\%). The discussion carried out of the stress that became parts and parcels of all sports competitions. It was realized that sports competition related to the cognitive functions, mental, and body control [4]. When athletes became overload in competitions, they might rapidly restore their attention to their performance [21]. Athletes' competition aspects conveyed their thinking about performance, goals that might have been set, self-confidence of physical and psychological attention, and weather and environmental conditions that might cause the results in athletes' different stress responses [5]. Conversely, athletes' overload competition they had attended in a huge schedule might negatively influence to their mental fatigue and physical condition. Hence, the mounting pressure of maintaining a high-level of performance throughout their competition had eroded the instability and nerves accordingly.

Table 4. Athletes' overload competition

\begin{tabular}{lllll}
\hline \multicolumn{1}{c}{ Likert's Scale } & Frequency & Percent & $\begin{array}{c}\text { Valid } \\
\text { Percent }\end{array}$ & $\begin{array}{c}\text { Cumulative } \\
\text { Percent }\end{array}$ \\
\hline 1.00 (Unstressed) & 1 & .3 & .3 & .3 \\
2.00 (Slightly stressed) & 4 & 1.4 & 1.4 & 1.7 \\
3.00 (Moderately stressed) & 29 & 10.0 & 10.0 & 11.7 \\
4.00 (Stressed) & 141 & 48.6 & 48.6 & 60.3 \\
5.00 (Highly stressed) & 115 & 39.7 & 39.7 & 100.0 \\
\hline Total & 290 & 100.0 & 100.0 & \\
\hline
\end{tabular}




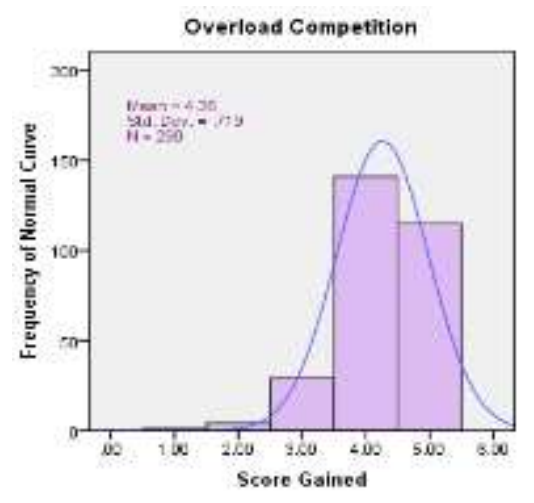

Fig. 4. Histogram on athletes' overload competition

Meanwhile, the athletes' self-confidence cohered with their day-to-day performance as revealed at the training center program. These determinants confirmed four potent contributions, such as excessive exercise training, hedonic lifestyle, aversive stimulation, and overload competition. This research accomplished 290 elite athletes in the various sport fields who were professionally trained at the training center program, Indonesian National Sports Committee Registry of Central Java Province. The results of descriptive statistics upon the athletes' stress determinants were shown in the following summary: excessive exercise training $(\mathrm{M}=4.51 ; \mathrm{SD}=.885)$, hedonic lifestyle $(\mathrm{M}=3.17 ; \mathrm{SD}=1.00)$, aversive stimulation $(\mathrm{M}=3.51 ; \mathrm{SD}=.985)$, and overload competition $(\mathrm{M}=4.25 ; \mathrm{SD}=.719)$. Mean and standard deviation of this descriptive statistics constituted with a 5-point-Likert scale to measure athletes' stress levels. Further, the values of skewness and kurtosis among these determinants were summarized as follows: excessive exercise training $(-.2 .197 ; 4.812)$, hedonic lifestyle (.028; -.399), aversive stimulation (-.148; -.645), and overload competition (-.880; 1.253) were insignificant for athletes' self-confidence influence when engaging in the day-to-day training center program. Of athletes' stress' skewness and kurtosis values, the data wee conditionally normal. However, the lowest mean of athletes' stress determinants referred to the hedonic lifestyle $(\mathrm{M}=3.17)$, whilst the highest mean was the excessive exercise training $(\mathrm{M}=4.51)$.

Pearson correlations analysis corresponded with the relationships among four perceived athletes' stress determinants as revealed in their training center program that was conducted by the Pearson product-moment correlation coefficients. However, the significant correlations among four determinants were significantly confirmed that $\mathrm{r}=.442, \mathrm{n}=290, \mathrm{p}<.000$. The highest level of significance value of athletes' stress determinants relied on their aversive stimulation $(.442 * *)$ associated with the lowest level of their traumatic experiences $\left(.126^{*}\right)$. However, the significance value among four perceived athletes' stress determinants was consequently positive and significant with $\mathrm{p}<.01$ level for 2 -tailed prediction. TABLE 5 comparably showed the correlation coefficients in the following sequences, namely: $.442^{* *}$, $.218^{* *}, .168^{* *}$, and $.153^{* *}$.

Table 5. Pearson Correlations of Athletes' Stress Determinants (Independent Variables)

\begin{tabular}{|c|c|c|c|c|c|}
\hline $\begin{array}{r}\text { Athletes' } \\
\text { Component }\end{array}$ & Stress & 1 & 2 & 3 & 4 \\
\hline
\end{tabular}




\begin{tabular}{|c|c|c|c|c|c|}
\hline \multirow{3}{*}{$\begin{array}{l}\text { Excessive } \\
\text { training }\end{array}$} & Pearson Correlation & 1 & .126 & $.153 * *$ & .084 \\
\hline & Sig. (2-tailed) & & $*$ & .009 & .154 \\
\hline & $\mathrm{N}$ & 290 & $\begin{array}{r}.032 \\
290\end{array}$ & 290 & 290 \\
\hline \multirow{4}{*}{ Hedonic lifestyle } & Pearson Correlation & .126 & 1 & .442 & .218 \\
\hline & Sig. (2-tailed) & $*$ & & $* *$ & $* *$ \\
\hline & $\mathrm{N}$ & .032 & 290 & .000 & .000 \\
\hline & & 290 & & 290 & 290 \\
\hline \multirow{3}{*}{ Aversive stimulation } & $\begin{array}{l}\text { Pearson Correla- } \\
\text { tion }\end{array}$ & $\begin{array}{r}.153 \\
* *\end{array}$ & $\begin{array}{r}.442 \\
* *\end{array}$ & 1 & $\begin{array}{r}168 \\
* *\end{array}$ \\
\hline & Sig. (2-tailed) & .009 & .000 & 290 & .004 \\
\hline & $\mathrm{N}$ & 290 & 290 & & 290 \\
\hline \multirow{3}{*}{$\begin{array}{l}\text { Overload } \\
\text { tion }\end{array}$} & $\begin{array}{l}\text { Pearson Correla- } \\
\text { tion }\end{array}$ & $\begin{array}{l}.084 \\
.154\end{array}$ & $\begin{array}{r}.218 \\
* *\end{array}$ & $\begin{array}{r}.168 \\
* *\end{array}$ & 1 \\
\hline & Sig. (2-tailed) & 290 & .000 & .004 & 290 \\
\hline & $\mathrm{N}$ & & 290 & 290 & \\
\hline
\end{tabular}

*. Correlation is significant at the 0.05 level (2-tailed).

**. Correlation is significant at the 0.01 level (2-tailed).

There were four determinants dealt with the principal components analysis (PCA) to address the factor analysis. Prior to identifying the components, the factor analysis suitability was tested to obtain the data. In this factor, the correlation matrix showed the coefficients availability of .107 and above. Meanwhile, the Kaiser Meyer-Olkin of sampling adequacy was .746 , passing through the expected value of .6 and the Bartlett's test of Sphericity showed $\mathrm{p}=$ .000 . This correlation matrix addressed the significance of statistics values and strengthened its correlation matrix factorability. The PCA showed the existence of four determinants with the Eigenvalue outreaching 1, was firmly estimated by $31.69 \%, 13.15 \%, 12.08 \%$, and $11.01 \%$ of the empirical data relatively (see TABLE 6). Herein, the scree plot conveyed the fix portrait by confirming four determinants. However, this scree plot was engaged in two axes disapproval for the further examination and verified by the parallel analyses. It addressed two axes with the Eigenvalue advocating the criterion values for the purposelessly brought about into the accessible matrix data, e.g.: 4 determinants $x 290$ athletes.

Table 6. Total Variance Obtainable From Athletes' Stress Determinants

\begin{tabular}{|c|c|c|c|c|c|c|c|}
\hline \multirow{2}{*}{ Determinants } & \multicolumn{2}{|c|}{ Initial Eigenvalue } & \multicolumn{3}{|c|}{$\begin{array}{l}\text { Extraction } \\
\text { Loadings }\end{array}$} & \multicolumn{2}{|c|}{$\begin{array}{l}\text { Rotation Sums o } \\
\text { Squared Loadings }^{\mathrm{a}}\end{array}$} \\
\hline & Total & $\begin{array}{l}\% \text { of } \\
\text { Variance }\end{array}$ & $\begin{array}{l}\text { Cumulative } \\
\%\end{array}$ & Total & $\begin{array}{l}\% \text { of } \\
\text { Variance }\end{array}$ & $\begin{array}{l}\text { Cumulative } \\
\%\end{array}$ & Total \\
\hline $\begin{array}{l}\text { Excessive } \\
\text { Exercise } \\
\text { Training }\end{array}$ & 2.535 & 31.691 & 31.691 & 2.535 & 31.691 & 31.691 & 1.539 \\
\hline $\begin{array}{l}\text { Hedonic Life- } \\
\text { style }\end{array}$ & 1.052 & 13.156 & 44.847 & 1.052 & 13.156 & 44.847 & 1.413 \\
\hline $\begin{array}{l}\text { Aversive } \\
\text { Stimulation }\end{array}$ & .966 & 12.081 & 56.927 & .966 & 12.081 & 56.927 & 1.100 \\
\hline $\begin{array}{l}\text { Overload } \\
\text { Competition }\end{array}$ & .881 & 11.012 & 67.939 & .881 & 11.012 & 67.939 & 1.187 \\
\hline
\end{tabular}


Extraction Method: Principal Component Analysis.

a. When components are correlated, sums of squared loadings cannot be added to obtain a total variance.

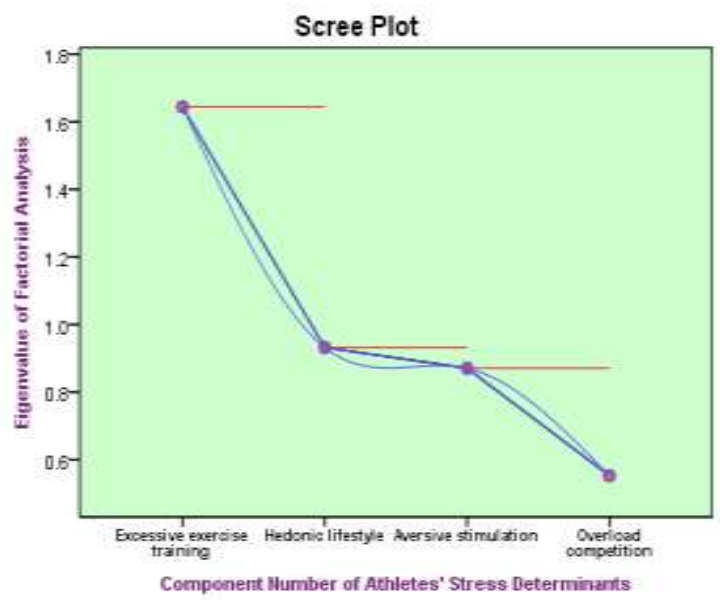

Fig. 5. Screen plot of athletes' stress determinants

The factorial analysis results (see TABLE 6) verified 2 substantial components with the value of $44.84 \%$. The first component showed $31.69 \%$, while the second component recorded $13.15 \%$. The oblimin rotation was confirmed to verify the first and second component of factorial analyses. The revolved output indicated the simple structure existence with both components referring to the squared loadings numbers and four influential determinants that resulted significantly on the first component. Furthermore, the clarification upon first and second components relied on the preliminary outputs on athletes' influential stress determinants scale. However, the first component showed the positive effect, whereas second component partially indicated the negative affect which had a weak negative correlation between both of them (see TABLE 7). The function of either positive or negative effect of Eigenvalue derivation was usable in scales separately. Of this factorial analysis, the description of athletes' conditional performance might be influential from their fear of failure, sadness, anger, frustration, dissatisfaction, increase in the training targets, injury, inconvenience, inability to cope with sensory information, and intolerance climates. All these sources potentially became athletes' stress appearance.

Table 7. Pattern \& Structure Matrix for PCA with The Oblimin Rotation of Two-Component of Athletes' Stress Determinants

\begin{tabular}{llllll}
\hline \multirow{2}{*}{ Determinants } & \multicolumn{2}{l}{ Pattern coefficients } & \multicolumn{2}{l}{ Structure coefficients } & \multicolumn{2}{c}{ Communalities } \\
\cline { 2 - 6 } & $\begin{array}{l}1^{\text {st }} \text { Compo- } \\
\text { nent }\end{array}$ & $\begin{array}{l}2^{\text {nd }} \\
\text { nent }\end{array}$ & $\begin{array}{l}\text { Compo- } \\
1^{\text {st }} \\
\text { nent }\end{array}$ & Compo- & $2^{\text {nd }}$ Component \\
\hline Aversive Stimulation & .639 & -.445 & N/A & -.442 & 1.000 \\
Hedonic Lifestyle & .574 & -.607 & N/A & -.1000 & 1.000 \\
Excessive Exercise & .312 & N/A & N/A & N/A & 1.000 \\
Training & & & & &
\end{tabular}


$\begin{array}{llllll}\text { Overload Competition } & .561 & \text { N/A } & .766 & \text { N/A } & 1.000\end{array}$

Note: major loadings for each item were in boldface

Of the overall analyses, this research realized to have limitations. The limitation firstly relied on the use of 'custom-tailored' self-rated questionnaire that was considered to be subjective by some athletes. Hence, this research suggested identifying some speculative fulfillment till the assertive validity and reliability testing were accurately examined. Secondly, the limitation accorded with the timely and data entry accuracy regarding athletes' eligible appropriateness situation conducted any deviation from this practice that might corrupt the data. Thirdly, the respondents of this research were entirely young athletes engaged in the training center program whose backgrounds might reflect to the multiple academic, social, and economic status, hence their understanding levels relating to the questionnaire fulfillment might be merely applicable to this cohort and might not be generalizable

\section{Conclusions}

Athletes' stress factors can be triggered from the internal and external contributions. All athletes' endeavor and activities daily shall reflect the stress levels which encourage the individual athletes to take actions. In this remarkable conclusion, athletes' stress levels in joining the sports' training center program can be verified in low, middle, and high-excessive levels. The experience of facing stress stably addresses athletes' tendency experiencing in the competitive positions of their self-esteem challenges. Stress management in sports leads to how the athletes cope, control, and reduce the deliverance of stress' negative existence. The major determinants of athletes' stress backgrounds constitute to the positive and constructive expectation among athletes. This means that athletes' excessive exercise training, hedonic lifestyle, aversive stimulation, and overload competition can be possibly reduced. On the other hand, this conclusion empirically record four influential determinants of athletes' stress as shown in the data analyses. These four determinants significantly stimulate sense of athletes' self-confidence to gain and maintain their best performance during joining in sports' training center program. Last but not least, the specially programmed attention towards athletes shall be addressed to control their stress levels remain low and manageable, to do with the imagery practices becomes adhered, and to observe athletes' mental rehearsal continuity prior to starting the relevant physical performance.

\section{Acknowledgement}

This research was funded by Daftar Isian Pelaksanan Anggaran (DIPA), Universitas Negeri Semarang, Indonesia.

\section{References}

[1] SH. Nassib, B. Mkaouer, SH. Riahi, SM. Wali, and S. Nassib, "The potential effects of relevant symptoms perceived by athletes and coping strategies upon athletics performance in competitive sport events". Journal of Psychological \& Clinical Psychiatry, vol. 10, no. 6, 2019, pp. 213-219. https://doi.org/10.15406/jpcpy.2019.10.00656 
[2] MJ. Hamlin, D. Wilkes, CA. Elliot, CA. Lizamore, and Y. Kathiravel, "Monitoring training loads and perceived stress in young elite university athletes". Frontiers in Physiology, vol. 10. no. 34, 2019, pp. 1-12. https://doi.org/10.3389/fphys.2019.00034

[3] WU. Eze, "The strategies for sports coach in managing stressful situations in sports competitions". International Journal of Current Research and Academic Review, vol. 3, no. 6, 2015, pp. 298-304.

[4] B. Brajendra, and T. Rajesh, "Stress management technique for athletes during sports: A critical review". Journal of Drug Delivery and Therapeutics, vol. 8, no. 5-s, 2018, pp. 67-72. https://doi.org/10.22270/jddt.v8i5-s.1956

[5] S. Hanton, O. Thomas, and SD. Mellalieu, Management of Competitive Stress in Elite Sport. In B. Brewer, Sport Psychology (1st edition), Blackwell Publishing, 2009.

[6] R. Singh, "Stress role in sports performance of athlete's". International Journal of Physical Education, Sports and Health, vol. 4, no. 3, 2017, pp. 278-280.

[7] JJ. Leddy, and J. Izzo, "Hypertension in athletes". Journal of Clinical Hypertension, vol. 11, no. 4, 2009, pp. 226-233. https://doi.org/10.1111/j.1751-7176.2009.00100.x

[8] CR. Halladay, Fear of Failure: An Exploratory Study of Division III Student-Athletes. Ithaca College Master of Science Thesis, Graduate Program in Exercise and Sport Sciences Ithaca, New York, 2003.

[9] R. Finnemore, "Perceptions of stress experienced by student-athletes in an education opportunity program". Counselor Education Capstone, vol. 44, 2017, pp. 1-29.

[10] JL. Rumbold, D. Fletcher, and K. Daniels, "A systematic review of stress management interventions with sport performers". Sport, Exercise, and Performance Psychology, vol. 1, no. 3, 2012, pp. 173-193. https://doi.org/10.1037/a0026628

[11] F. Moen, M. Hrozanova, TC. Stiles, and F. Stenseng, "Burnout and perceived performance among junior athletes-Associations with affective and cognitive components of stress". Sports, vol. 7, no. 171, 2019, pp. 1-11. https://doi.org/10.3390/sports7070171

[12] LJ. Cronbach, and RJ. Shavelson, "My current thoughts on Coefficient Alpha and successor procedures". Educational and Psychological Measurement, vol. 64, no. 3, 2004, pp. 391-418. https://doi.org/10.1177/0013164404266386

[13] D. Ary, LC. Jacobs, and CK. Sorensen, Introduction to Research in Education (8th Ed.). Belmont: Wadsworth, Cengage Learning, 2010.

[14] J. Pallant, SPSS Survival Manual: A Step by Step Guide to Data Analysis Using SPSS (4th Ed.). New South Wales: Allen \& Unwin, 2011.

[15] RE. Reigal, JA. Vázquez-Diz, JP. Morillo-Baro, A. Hernández-Mendo, and V. Morales-Sánchez, "Psychological profile, competitive anxiety, moods and self-efficacy in beach handball players". International Journal of Environmental Research and Public Health, vol. 17, no. 241, 2019, pp. 113. https://doi.org/10.3390/ijerph17010241

[16] CJ. Chang, M. Putukian, G. Aerni, AB. Diamond, ES. Hong, YM. Ingram, CL. Reardon, and AT. Wolanin, "Mental health issues and psychological factors in athletes: Detection, management, effect on performance, and prevention: American medical society for sports medicine position statement - executive summary". British Journal of Sports Medicine, vol. 54, no. 4, pp. 216-220. https://doi.org/10.1136/bjsports-2019-101583

[17] S. Caselli, AV. Sequì, E. Lemme, F. Quattrini, A. Milan, F. D’Ascenzi, A. Spataro, and A. Pelliccia, "Prevalence and management of systemic hypertension in athletes". The American Journal of Cardiology, vol. 119, 2017, pp. 1616-1622. http://doi.org/10.1016/j.amjcard.2017.02.011.

[18] IS. Perry, and YJ. Katz, "Pre-performance routines, accuracy in athletic performance and selfcontrol". Athens Journal of Sports, vol. 2, no. 3, 2015, pp. 137-152. https://doi.org/10.30958/ajspo.2-3-1

[19] G. Santi, and L. Pietrantoni, "Psychology of sport injury rehabilitation: a review of models and interventions". Journal of Human Sport \& Exercise, vol. 8, no. 4, 2013, pp. 1029-1044. https://doi.org/10.4100/jhse.2013.84.13 
[20] DR. Sumekto, and H. Setyawati, "Revealing lecturer's paralinguistic attribution: How the visual manner contributes to students' non-cognitive skills". Indonesian Journal of Applied Linguistics, vol. 9, no. 3, 2020, pp. 559-571. https://doi.org/10.17509/ijal.v9i3.23206

[21] JN. Gilbert, W. Gilbert, and C. Morawski, "Coaching strategies for helping adolescent athletes cope with stress". JOPERD, vol. 78, no. 2, 2007, pp. 13-24. https://doi.org/10.1080/07303084.2007.10597967

[22] C. Faure, and KM. Appleby, "The logistical management of the organizational stress of elite "pipeline" athletes: Interventions of national performance directors in an olympic year". The Journal of SPORT, vol. 3, no. 2, 2014, pp. 139-183.

[23] C. Wilson, EV. Bennett, AD. Mosewich, GE. Faulkner, PRE. Crocker, "The zipper effect: Exploring the interrelationship of mental toughness and self-compassion among Canadian elite women athletes". Psychology of Sport \& Exercise, vol. 40, 2018, pp. 61-70. https://doi.org/10.1016/j.psychsport.2018.09.006

[24] A. Kaya, "Decision making by coaches and athletes in sport". Procedia - Social and Behavioral Sciences, vol. 152, 2014, pp. 333-338. https://doi.org/10.1016/j.sbspro.2014.09.205

[25] R. Sheinbein, "Psychological effect of injury on the athlete: A recommendation for psychological intervention". AMAA Journal Fall/Winter, 2016, 8-10. 